\title{
Student pro-sociality: Measuring institutional and individual factors that predict pro-social behaviour at university
}

\author{
Chris Stiff ${ }^{1}$ (D) $\cdot$ Harriet E. S. Rosenthal-Stott ${ }^{2} \cdot$ Stephanie Wake $^{3} \cdot$ Amelia Woodward $^{1}$
}

Published online: 18 April 2019

(C) The Author(s) 2019

\begin{abstract}
Students operate within a bounded social context and often face decisions regarding whether to pursue selfish or group-level benefit. Yet little work has examined what predicts their behaviour towards fellow students. This work addresses this gap by investigating what factors may predict students' performance of pro-social actions at university, and how an institution may maximise such behaviour. Study 1 created the student pro-sociality scale, used to measure these tendencies in students. In study 2 , 428 students from $25 \mathrm{UK}$ universities took part an online survey study using this scale, and several other pre-existing measures of possible predictors. Analysis suggested that of those factors examined, role clarity, affective commitment, empathy, and perspective-taking emerged as the most influential. This first foray into this area can now inspire further research in finding the effective ways of fostering pro-social behaviour in students.
\end{abstract}

Keywords Pro-social $\cdot$ Student $\cdot$ University $\cdot$ Survey $\cdot$ Scale development

Imagine the following scenario: a student takes a library book from the shelf and reads it at a nearby desk. When they are finished, do they replace it, or leave it in the now-vacant study space to be found by the librarian? Or, imagine a student eating their lunch in the cafeteria. When they are finished, do they place their remains in the bin and return their tray, or leave their table littered with the detritus from their meal? What influences whether a student acts in a fashion that is pro- or anti-social? What predicts whether a student acts in a way that selfishly benefits them, or philanthropically benefits the student body as a whole?

Outside of universities, these kind of spontaneous prosocial behaviours (e.g. working outside contracted hours, performing duties beyond one's job description) have been

Electronic supplementary material The online version of this article (https://doi.org/10.1007/s12144-019-00256-3) contains supplementary material, which is available to authorized users.

Chris Stiff

c.stiff@ keele.ac.uk

1 School of Psychology, Keele University, Keele, UK

2 Durham University, Durham, UK

3 York University, Toronto, Canada shown to be extremely beneficial in terms of economic success and employee retention. Meta-analyses have indicated that high levels of pro-sociality are linked with better performance, and lower levels of employee exit and absenteeism (Podsakoff et al. 2009). Productivity and customer satisfaction were also substantially higher in companies where employees frequently engaged in pro-social acts. Clearly, the performance of these kinds of behaviours is desirable and valuable in the maintenance of a productive system. At university, how to promote pro-social behaviour has implications for improving the educational experience for students, and thus is a vital consideration for higher education authorities.

Within the extant literature there is little work that has examined how these kinds of behaviours may manifest in a higher education context, nor investigated what factors may propagate them. Although the student population is often used in research on pro-sociality (and indeed other research areas), the educational setting is not usually the embedding context. That is, students are rarely asked about their actions specifically at university, and how the frequency of these actions may be moderated.

Here, we seek to explore this link by examining pro-social actions performed by students within a university context and also seek to examine what factors predict such behaviours. We have defined pro-social behaviour in this work as simply "behaviour which benefits others". 


\section{Predicting Students' Pro-social Behaviours: Institutional Factors}

Previous research has indicated several factors that may predict pro-social action within an organizational context. For example, Kamdar et al. (2006) demonstrated that perceptions of the way superiors meted out rewards and punishments - i.e. procedural justice - positively influences performance of prosociality. Meierhans et al. (2008) have indicated that support from authority was another key factor in predicting pro-social behaviour in employees. Finally, clarity of one's role in an institution also positively predicts pro-social behaviours. While attending university, students are subject to formal rules and regulations, and are integrated within a hierarchical structure wherein they can be subject to diktats and declarations from authority figures. Therefore, we would expect these factors would also be influential in predicting student prosociality.

An employee's perceptions and assessment of their employing institution are clearly important when predicting pro-social behaviour. Organizational commitment - i.e. employee's feelings of loyalty and willingness to work towards an organization's objectives (Pierro et al. 2013) - is a consistent positive predictor for pro-social behaviour in traditional office environments (Schappe 1998) and also in other, less organization-like settings, such as teachers in schools (Feather and Rauter 2004). More elaborate models tend to conceptualise commitment as a multi-faceted construct. For example, Meyer and Allen (1991) posited three kinds of commitment: affective (an emotional attachment to an organization), continuance (a need to stay with an organization because of the costs associated with leaving the organization), and normative (feelings of obligation towards an organization). Meierhans et al. (2008) have demonstrated affective and normative commitment are most predictive of pro-social behaviours within organisations. We believe that these kinds of commitment to one's university may therefore be important when examining students' pro-sociality.

To take a more general view, the extant literature suggests that efforts by an organization to support and nurture its employees facilitates pro-sociality. Within universities, this is often manifested as pastoral care, wherein students can seek assistance with academic or personal issues (e.g., Van Van Laar and Easton 1994). It is possible then that the perceived presence of such a support system within the university may also be predictive of pro-social behaviour.

\section{Predicting Students' Pro-social Behaviour: Individual Factors}

The conflict between whether to act in a way that maximises payoffs for oneself, or to optimise payoffs for everyone, is known as a social dilemma (Bruins et al. 1989; Dawes and Messick 2000) and these conflicts have been subject to considerable scrutiny in the literature. For example, the decision to take public transport over a private car to work is a social dilemma (Van Vugt et al. 1996); while driving is quicker, and allows greater flexibility, if all citizens drove the result is rush hour traffic jams and high levels of pollution. Many other socially responsible behaviours can also be considered social dilemmas - e.g. recycling (Ohnuma et al. 2005) - and students are faced with similar dichotomies when deciding how to behave at university (Abele et al. 2010). Acting pro-socially can be thought of as the "cooperative" option in a social dilemma, as this seeks to optimise payoffs for all concerned. Maximising the likelihood of this behaviour is extremely important, as witnessing "selfish" actions tends to cause negative emotional states (Martinez et al. 2011; Stouten et al. 2006) and a contagion of non-cooperation in order to avoid exploitation (Bruins et al. 1989; Robbins 1995; Schnake 1991).

To this end, there are numerous methods highlighted by previous research that can be used to diminish selfish actions by those in a social dilemma situation and heighten the likelihood of pro-social behaviour. Several individual differences in particular have been shown to be predictive of cooperation. For example, high levels of social identity (Brewer and Kramer 1986) and empathy for others (Rumble et al. 2010) both tend to lead to cooperation over defection. Dispositional trust of others is also a key indicator in promoting cooperation (De Cremer et al. 2001), as is the extent that individuals value others' opinion of them - their level of self-monitoring (Danheiser and Graziano 1982).

Beyond the social dilemma domain, other factors also explain pro-social behaviour. Gratitude plays a role in philanthropic actions (McCullough et al. 2002), the assumption being that those who are more grateful to others are higher in agreeableness, which in turn leads to pro-sociality (see Koole et al. 2001).

\section{An Overview of the Current Work}

The primary aim of this work was to examine some of the key predictors of students' pro-social behaviour in a university context; that is, what are the institutional and individual factors that will result in students engaging in pro-social behaviour at university. To this end, in Study 1 we developed a scale (using focus groups and a pilot) to measure student pro-sociality. In Study 2, we distributed our scale with measures of institutional (procedural fairness, perceived support, pastoral care, clarity of role, organisational commitment) and individual (social identity, empathic concern / perspective taking, trust, self-monitoring, gratitude) predictors of pro-social behaviour to examine: (1) which factors correlated with incidents of student pro-sociality; and (2) which factors were the 
most influential in the prediction of students' pro-social behaviour. Overall, we aimed to gain a clearer picture of precisely how we may foster cooperative and socially responsibility behaviour from the student body and maximize the positivity of the educational experience for those attending university.

\section{Study 1a - Focus Groups}

\section{Method}

\section{Participants}

Focus groups took place at four UK universities. A total of 31 participants (20 female) were involved, aged between 18 and $24(\mathrm{M}=20.13$; $\mathrm{SD}=1.22)$. The size of the focus groups ranged from 6 to 9 participants: Focus group 1 (Durham University) consisted of 9 participants (6 female; 3 male), aged 19-22 ( $\mathrm{M}=20.44 ; \mathrm{SD}=0.88)$; Focus group 2 (University of Birmingham) consisted of 6 participants (2 female; 4 males), aged 19-24 ( $\mathrm{M}=20.67$; $\mathrm{SD}=1.97)$; Focus group 3 (Keele University) consisted of 9 participants ( $7 \mathrm{fe}-$ male; 2 male), aged 18-22 $(\mathrm{M}=19.67$; $\mathrm{SD}=1.12)$; and Focus group 4 (University of Leicester) consisted of 7 participants ( 5 female; 2 male), aged 19-21 ( $M=19.83$; $\mathrm{SD}=0.75)$.

The majority of participants identified as straight/ heterosexual $(N=28$; gay/lesbian $N=2$; undisclosed $N=1)$, were British $(N=21$; other nationalities $N=9$; undisclosed $N=1)$, and White $(N=19$; other ethnicities $N=10$; undisclosed =2). The focus groups ran for $50 \mathrm{~min}$ and participants were paid $£ 10$ for taking part. Informed consent was obtained from all individual participants included in the study.

\section{Procedure}

Following ice-breaker activities, participants were asked to discuss in pairs/threes what they considered "pro-social behaviour" to be, and to produce their own definitions. This was designed to promote engagement with the activity. Following whole-group discussion, participants were presented with the simple pro-social behaviour definition "behaviour that benefits others" - and were given examples from the organisational behaviour literature (e.g., washing people's cups in staffroom; helping someone with workload; attending non-mandatory meetings). Participants were then asked to generate prosocial behaviours that exist at university in their pairs/threes. Finally, participants engaged in wholegroup discussion where they were asked to produce their "best" 15-20 pro-social behaviours (dependent on timerestraints) - i.e. the behaviours that best exemplified the parameters given - by combining/refining items already discussed. No specific method was given to arrive at these items, and most groups simply engaged in discussion amongst themselves to record these with little disagreement.

\section{Results}

The 15-20 pro-social behaviours generated in each focus group were combined, resulting in 48 unique items after excluding duplications. Due to the large number of duplications resulting in a lower number of items than expected, the researchers examined the original prosocial behaviours generated in the paired generation stage and identified a further 8 unique items that were not included by the participants at the group stage. For example, "respect lecturers" led to the creation of the "respect support staff" item by researchers, creating a total of 56 items. The majority of these items (54) were positive in valence, therefore, in order to reduce response bias, the phrasing of 12 items were reversed, such that one-quarter of the questions (14) were negative in valence. In addition, items that included terms that were unique for some universities (e.g. those that referred to a specific building) were edited to be more generic.

\section{Study $1 \mathrm{~b}$ : Piloting the Scale}

\section{Method}

\section{Participants}

Eighty participants (40 female) took part; twenty participants (10 female; 10 male) were recruited from each of the four universities as Stage 1a. Participants ranged in age from 18 to $35(M=20.47 ; S D=2.85)$ and included more undergraduates $(N=73)$ than postgraduates $(N=6 ; 1$ undisclosed). The majority of participants were British $(N=69$; BritishAmerican, $N=1)$, with the remaining participants from a range of countries (USA $(N=2)$; China; Cyprus; Germany; Mongolia; Nigeria; Pakistan; Saudi Arabia; 1 undisclosed). The majority of participants were White $(N=57)$, followed by Asian $(N=18)$, Black $(N=2)$, mixed ethnicity $(N=1)$ and Yonbu ( $N=1 ; 1$ undisclosed). The majority of participants identified with being straight/heterosexual $(N=70)$, the remaining participants identified with being gay/lesbian $(N=$ 5) or bisexual/pansexual ( $N=4 ; 1$ undisclosed). Participants were paid $£ 5$ for taking part.

\section{Procedure and Materials}

Participants were approached on the campuses of the four universities. If they agreed to take part, they provided with the survey document which consisted of the student prosociality scale items, followed by demographic items. 
The student pro-sociality scale listed the 56 items and asked participants to report how often they engaged in the activities on a 5-point scale. Responses on the scale were: never (1); rarely (2); sometimes (3); often (4); and always (5). The order of items was randomized, with the items presented in the same order for all participants. Following completion of the scale, participants were asked to indicate their age, gender, sexual orientation, ethnicity, and nationality. Participants were also asked to provide optional feedback on the questionnaire, including potential improvements that could be made.

\section{Results}

Refinement of Items Four items were flagged as problematic by some participants. These were items that were only applicable if somebody was a smoker ("Only smoke in designated/ respectful areas"), drinker ("Be aware of alcohol intake and behaviour when intoxicated"), car owner ("Share car journeys"), or did their laundry in a shared machine ("Not take laundry out of washing machine on time"). An additional three items were removed for having limited range $(<3)$ : "Be polite/have good manners"; "Look out for others"; and "Take care of university property". Five further items were removed as they were deemed to be measures of "respecting others" rather than "helping others" (i.e. "Respect university rules and regulations"; "Respect university support staff (e.g., security/ student support/administrative staff)"; "Be respectful in lectures"; "Respect the public around campus", and "Respect university staff members (lecturers))". We focus here on observable, physical behaviours; by contrast, while "respect" is often pro-social it may not be visible and may only manifest as an attitude towards another person, rather than a behaviour.

Factor Analysis A varimax rotation was run on the remaining 44 items. $\mathrm{KMO}=.493$. Items less than .5 in the anti-image correlation matrix were removed, which resulted in the removal of 25 items. A second varimax rotation was performed on the remaining 19 items, $\mathrm{KMO}=.702$. This indicated that $24.96 \%$ of the variance in the unrotated solution was explained by a single factor - see Table 1 . The seven items not loading onto this factor were removed.

The remaining 12 items were then subjected to confirmatory factor analysis, with all items loading onto a single "latent" (i.e. pro-social behaviour) measure. In assessing goodness of fit, indices of 0.9 or greater indicate a good match between the model and data, with an RMSEA ideally below 0.8 with a non-significant $p$ value (Byrne 1999; Schreiber et al. 2006). Comparative goodness-of-fit indices were therefore moderate - see Table 2. The Hoelter figure was 71 indicating that our sample size (80) was sufficient for this analysis.
These 12 items then comprised our pro-sociality scale and were used in Study 2.

\section{Study 2}

\section{Method}

\section{Participants}

Four-hundred-and-twenty-eight participants took part in exchange for entry into a prize-draw to win Amazon vouchers. Participants were recruited by contacting universities across the UK. Methods of recruitment included contacting students directly (email; flyers; posters) and advertising on social media (twitter; Facebook; internal online student message boards). Participants were recruited from 25 different universities (undisclosed $N=28$ ), with the majority of participants from Canterbury Christ Church University $(N=96)$, Durham University $(N=92)$, University of Glasgow $(N=75)$ Keele University $(N=58)$, and the University of Cumbria $(N=31)$. The number of participants from other universities ranged from 1 to 7 . The majority of participants were female $(N=$ 324; Male $N=98$; $T$ ransgender $N=1$; undisclosed $N=5$ ) and undergraduates $(N=339$; postgraduate $N=70$; undisclosed $N=19$ ). Age ranged from 18 to 64 (undisclosed $N=18$; $\mathrm{M}=23.29 ; \mathrm{SD}=7.03$ ). Informed consent was obtained from all individual participants included in the study.

\section{Design}

The survey was distributed online, and access was provided by distribution of a web link. All participants completed the student pro-sociality scale first. Participants were randomly assigned to one of four versions that counterbalanced the order of the questionnaires (order $1 N=102$; order $2 N=107$; order $3 N=99$; order $4 N=120$ ). The orders were either the institutional measures followed by the individual measures, or the individual measures followed by the institutional measures. In addition, the order of the measures was reversed for half of the participants. Therefore, the four orders were: (1) institutionalindividual; (2) individual-institutional; (3) institutional reversed-individual reversed; (4) individual reversedinstitutional reversed. Participants then received the demographic information.

\section{Materials}

With the exception of the student pro-sociality scale and pastoral care scale, all measures were presented with the same 7-point Likert-type scale: Strongly Disagree (1); Disagree (2); Slightly Disagree (3); Neutral (4); Slightly Agree (5); Agree (6); Strongly Agree (7). Institutional 
Table 1 Factor analysis of items for pro-sociality scale

\begin{tabular}{|c|c|c|c|c|c|c|c|}
\hline Item & 1 & 2 & 3 & 4 & 5 & 6 & 7 \\
\hline Volunteer & & & & .524 & & & \\
\hline Be involved in lectures/discussions & & & & & & .448 & \\
\hline Keep the campus tidy & .694 & & & & & & \\
\hline Provide emotional support to peers & .505 & & & & & & \\
\hline Clean away tables after eating in university dining/cafe areas & .536 & & & & & & \\
\hline Offer/give fellow students advice & .592 & & & & & & \\
\hline Keep organised (bring work to student meetings) & & & & & .585 & & \\
\hline Be Friendly & & & .594 & & & & \\
\hline Be punctual for meetings/lectures & .477 & & & & & & \\
\hline Pick up other peoples rubbish & & & & & & 625 & \\
\hline Help new students & .420 & & & & & & \\
\hline Let others know when you have guests & & & .481 & & & & \\
\hline Efficiently use space in communal areas (e.g. libraries cafes) & .590 & & & & & & \\
\hline Be quiet in library & .525 & & & & & & \\
\hline Recycle (be green) & .510 & & & & & & \\
\hline Turn up for arranged events/appointments & .570 & & & & & & \\
\hline Respect others' belongings & .718 & & & & & & \\
\hline Volunteer to take part in others research studies/surveys & & & & & & & .440 \\
\hline Keep communal areas tidy & .536 & & & & & & \\
\hline
\end{tabular}

Only the highest factor loading for each item is shown, for clarity

measures were adapted from the original version to be applicable to a university setting.

\section{Student Pro-sociality}

Participants were presented with the 12 -item scale created in Study 1. Participants were asked to state how often they engaged in the activities on a scale of: Never (1); Rarely (2); Sometimes (3); Often (4); Always (5). See Appendix.

\section{Institutional Measures}

Procedural Fairness Two scales were used to measure procedural fairness. Four items were adapted from Byrne, (1999; see also Kamdar et al. 2006), for example I can count on my supervisor to have fair policies became I can count on my university to have fair policies. Fifteen items were adapted

Table 2 Goodness of fit indices for 12-item prosociality scale

\begin{tabular}{ll}
\hline Index & Value \\
\hline NFI & .69 \\
RFI & .55 \\
IFI & .87 \\
CFI & .85 \\
RMSEA & .08 \\
\hline
\end{tabular}

from Niehoff and Moorman (1993), constituting two subscales of formal procedures (6 items) and interactional justice (9 items).

Perceived Support Four items adapted from Meierhans et al. (2008, taken from Eisenberger et al. 1986) were used to measure perceived organizational support. E.g. help is available from university staff when I have a problem.

Pastoral Care 16 items were adapted from a scale originally designed to measure satisfaction with chaplains in healthcare settings (Flannelly et al. 2007). This was adapted to examine students' perceptions of the extent to which university staff engaged in pastoral care activities (e.g. communicate caring for you). Four items were excluded due to non-relevant religious references (e.g., Take the time to pray with you). The original 5-point scale was used: Not at All (1); Slightly (2); Moderately (3); Very Much (4); Not Certain (5); with an additional not applicable option.

Clarity of One's Role Six items (adapted from Bettencourt and Brown 2003; taken from Rizzo et al. 1970) measured role conflict (3 items, e.g., I receive incompatible requests from two or more people) and role ambiguity (3 items, e.g., I know what my responsibilities at university are). 
University Commitment An organisational commitment scale (Meierhans et al. 2008) was adapted to measure participants' commitment to their university. Twelve items measured three subscales: affective university commitment (5 items, e.g., I am proud to belong to my university); normative university commitment (4 items, e.g., I would somehow feel guilty if I left my university now); and affective supervisory commitment (3 items, e.g., university staff successes are my successes).

\section{Individual Measures}

Social Identity Two scales measured social identity. The first scale was specifically designed to measure university identification (Johnson et al. 2012), and consisted of eight items measuring the two subscales of affective social identity (4 items, e.g., I feel happy to be a student in the university) and cognitive social identity (4 items, e.g., My self-identity is based in part on my membership in the university). The second scale was adapted from the identity subscale of Luhtanen and Crocker (1992) collective self-esteem scale and consisted of four items (e.g., the university I belong to is an important reflection of who I am).

Empathic Concern Seven-items measured empathic concern. In line with Kamdar et al. (2006) the empathic concern subscale of the Interpersonal Reactivity Index scale (Davis 1980) was used. This consisted of seven items (e.g., I am often quite touched by things that I see happen).

Perspective Taking Also in line with Kamdar et al. (2006), the perspective taking subscale of the Interpersonal Reactivity Index scale (Davis 1980) was included, which consisted of nine-items (e.g., Before criticizing somebody, I try to imagine how I would feel if I were in their place).

Trust Five-items taken from De Cremer et al. (2001; see also Yamagishi 1986) measured trust (e.g., Most people are basically honest).

Self Monitoring Thirteen items from Lennox and Wolfe's (1984) revised scale were used to measure self-monitoring. (e.g. in social situations, I have the ability to alter my behaviour if I feel that something else is called for).

Gratitude Five items from McCullough et al. (2002) were used to measure grateful disposition in participants (e.g. I feel thankful for what I have received in life).

\section{Results}

\section{Assessment of Pro-sociality Scale}

As before, a confirmatory factor analysis was performed to examine the fit between our data and the pro-sociality scale. All 12 items were loaded onto a single "latent" factor. This again yielded a moderate fit, strengthening the validity of our scale - see Table 3 .

\section{Student Pro-sociality and Predictor Variable Correlations}

Reliability analyses on predictor scales showed high reliability with all $\alpha>$.700, except for trust. Means/totals of items were then calculated (as per scale instructions) and entered into a bivariate correlation. All assumptions for correlations were met (i.e. data was interval/ratio, homoscedastic, and did not contain significant outliers). All predictors except trust, selfmonitoring, and normative commitment were shown to be significantly positively correlated with pro-sociality - see Table 4 .

\section{Student Pro-sociality Regression Analyses}

An analysis of standard residuals showed the data contained no outliers (Standardised Residual Minimum $=-2.86$; Standard Residual Maximum = 2.95). The data met the assumptions of independent errors (Durbin-Watson Value = 2.09). The histogram of standardised residuals indicated that the data contained normally distributed errors, as did the normal P-P plot of standardised residuals. The scatterplot of standardised residuals showed that the data met the assumptions of homogeneity of variance and linearity. The data also met the assumptions of non-zero variances. Table 5 shows the inter-correlations between all predictor variables.

An initial regression analysis was performed with all variables entered into the model simultaneously. This model (model 1) explained a significant amount of variance in prosociality scores $\left(\mathrm{F}(15,411)=7.23, p<.01, \mathrm{R}^{2}=20.9 \%\right.$, adjusted $\mathrm{R}^{2}=18.0 \%$. The average variance inflation factor was 2.05 , and all tolerances were greater than .02, suggesting multicollinearity was not an issue. An examination of the in-

Table 3 Goodness of fit indices for 12-item prosociality scale derived from main sample

\begin{tabular}{ll}
\hline Index & Value \\
\hline NFI & .73 \\
RFI & .75 \\
IFI & .89 \\
CFI & .88 \\
RMSEA & .07 \\
\hline
\end{tabular}


Table 4 Means, standard deviations, scale reliabilities and student pro-sociality and the predictor variables zero order correlations between

\begin{tabular}{llll}
\hline Variable & Mean (SD) & Correlation with student pro-sociality & $\alpha$ \\
\hline Student pro-sociality & $4.02(.38)$ & - & .70 \\
Institutional factors & & & \\
Procedural fairness & & & \\
Byrne scale & $5.40(.052)$ & $.193^{*}$ & .81 \\
Niehoff scale & $4.91(1.06)$ & $.234^{*}$ & .95 \\
Percevied support & $4.59(.74)$ & $.215^{*}$ & .83 \\
Pastoral support & $3.15(.64)$ & $.224^{*}$ & .88 \\
Role clarity & $5.33(.93)$ & $.270^{*}$ & .76 \\
Organisational commitment & & & .88 \\
Affective & $5.12(1.31)$ & $.228^{*}$ & .75 \\
Normative & $4.30(1.38)$ & .07 & .85 \\
Affective supervisory & $3.43(1.44)$ & $.142^{*}$ & \\
Individual factors & & & .88 \\
Social identity & & & .83 \\
Johnson scale & $4.98(1.15)$ & $.171^{*}$ & .85 \\
Luhtanen \& Crocker scale & $4.07(1.44)$ & $.141^{*}$ & .81 \\
Empathic concern & $5.25(.92)$ & $.301^{*}$ & .74 \\
Perspective taking & $4.89(.94)$ & $.307^{*}$ & .59 \\
Trust & $3.60(.89)$ & -.06 & .72 \\
Self-monitoring & $4.02(.70)$ & -.08 & .82 \\
Gratitude & $5.80(.99)$ & $.260^{*}$ & \\
\hline
\end{tabular}

Figures in brackets indicate SD

$* p<.05 . * *=p<.01$

dividual predictors showed that role clarity, empathic concern, and perspective taking all contributed significantly to the model. In order to reduce the likelihood of suppressor effects, a backward linear regression was then performed using all predictors. This new model (model 2) was also significant $(\mathrm{F},(4,422)=25.63, p<.01)$, and accounted for nearly $20 \%$ of the variance $\left(\mathrm{R}^{2}=19.3 \%\right.$, adjusted $\left.\mathrm{R}^{2}=18.6 \%\right)$. This new model also showed affective organizational commitment contributed significantly to the model - see Table 6 . Finally, a hierarchical regression was performed using only model 1's predictors at stage 1, and adding the affective organizational commitment at stage 2 . The $\mathrm{R}^{2}$ change between models was significant ( $p=.019$ ). Thus, we conclude that model 2 is the best model for explaining variance in student pro-sociality.

\section{Discussion}

An enormous amount of psychological literature has examined the performance of pro-social behaviour in small groups (e.g. laboratory based "game theory" studies) or in a more generalised fashion with an organisational context. This paper is the first to examine such actions outside of a traditional organization context. Specifically, we examined what might predict similar kinds of pro-social behaviour performed by students, within universities. We posited that two kinds of variable would be of interested: those relating to the individual (e.g. personality traits) and those relating to the institution (i.e. the perception of one's role within the university). To investigate this, we first created new scale to measure student prosociality and then measured what factors may predict this behaviour.

Overall, we found strong support for our ideas. There was a high prevalence of pro-social behaviour enacted at all participating universities, suggesting that this kind of benevolence is widely enacted. Although most predictors showed strong correlations with student pro-sociality (the exceptions being normative commitment, trust and selfmonitoring), four emerged as the most influential predictors in our regression model. Of these, it is worth noting that two were individual factors - empathic concern and perspective taking - and two institutional factors - affective organizational commitment and role clarity. Clearly, student pro-sociality is a complex construct, and is influenced by both individuals' dispositions / personalities and by the institutional context. 


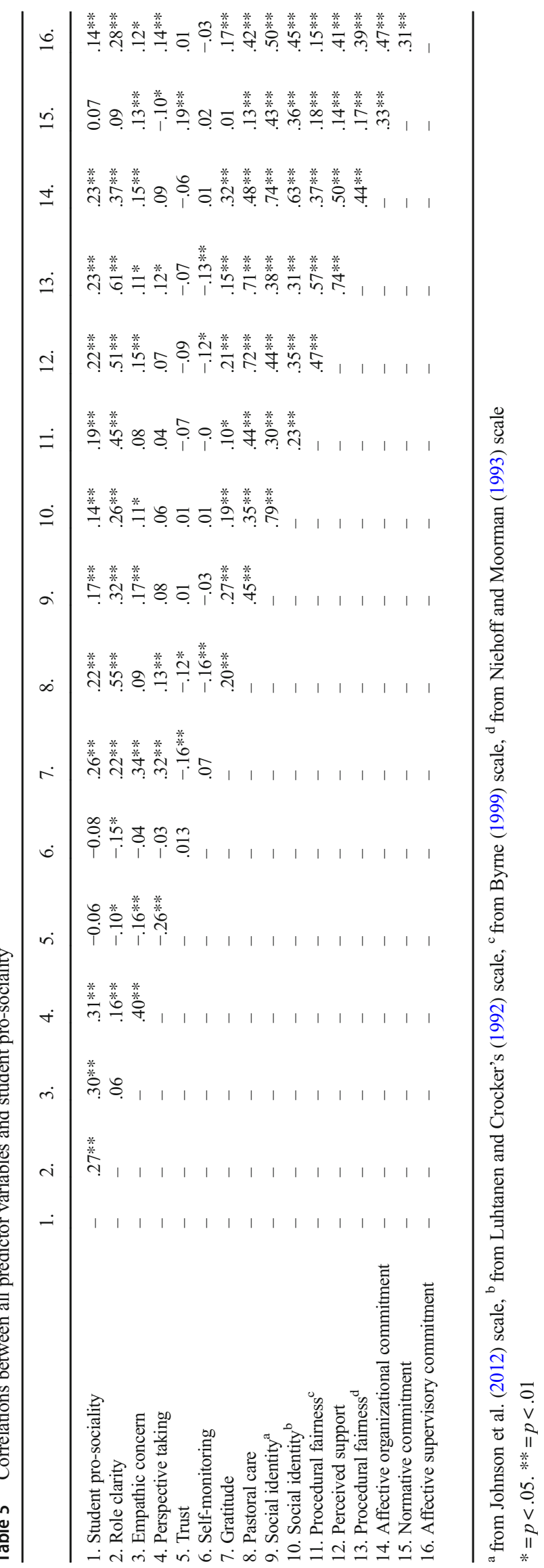

Applications of Findings - Increasing Student Pro-sociality

Having identified what seem to be the key predictors of student pro-sociality, we can now posit a number of routes that can be taken to increase their occurrence. Empathy and perspective taking can often be increased by simply asking individuals to consider the viewpoints of others. Batson et al. (1997) instructed participants to listen to an individual undergoing a (fake) stressful situation, and then asked them to imagine how the actor felt, or how they would feel in that same situation. Both strategies increased feelings of empathy. More long-term training in perspective taking is also often administered to medical students. Winefield and ChurHansen (2000) examined the effectiveness of a programme where participants attended classes teaching them how to treat distressed patients, develop rapport, and deal with difficult situations. Most participants showed an increase in empathy after they had completed such training compared with baseline measures (see also Shapiro et al. 2006 for a similar method).

Institutional predictors of student pro-sociality are perhaps easier for a university to address. An employee's role is usually indicated through descriptions of the behaviours expected of them, and the norms and values adopted by someone in that position (Brookes et al. 2007). Clear communication of these expectations should increase an individual's role-clarity, which - according to our findings - should also increase performance of students' pro-social behaviour. However, this information is usually provided by an employee's manager (Shivers-Blackwell 2004), which may complicate matters in a university context where a student's "superior" may not be clear. Role making is also a dynamic process between employee and manager and requires continued communication and clarification (Brunetto et al. 2011; Hassan 2013) again, how this may operate outside of organizations is difficult to discern. Individuals may also differ on their need for clarity which may moderate any relationship between role information and action (O'driscoll and Beehr 2000). Despite these issues, we can posit, at minimum, that some kind of induction process wherein students are clearly informed of the expectancies placed on them by their institution should facilitate pro-social behaviour. Sawyer's (1992) examination of role clarity found that feedback or recognition for performing appropriately within a role's parameters is also an important part of this process. Therefore, students should receive a clear indication that they are behaving "correctly" in order to best foster pro-social behaviour.

Only affective commitment was predictive for student prosociality, contrary to the findings of Meierhans et al. (2008) who found both affective and normative commitment were predictive of pro-social behaviours within organisations. This may be because a students' involvement with a university is finite in length; they are expected to leave, and therefore normative commitment is nullified, unlike in an organisational 
Table 6 Forced entry and backward entry regression analyses for predictors on student pro-sociality

\begin{tabular}{|c|c|c|c|c|}
\hline \multirow[b]{3}{*}{ Variable } & \multicolumn{4}{|c|}{ Student pro-sociality } \\
\hline & \multicolumn{2}{|c|}{ Model 1} & \multicolumn{2}{|c|}{ Model 2} \\
\hline & $\mathrm{B}$ & SE B & $\mathrm{B}$ & SE B \\
\hline Role clarity & $.057 * *$ & .024 & $.077 * *$ & .020 \\
\hline Empathic concern & $.073 * *$ & .021 & $.082 * *$ & .020 \\
\hline Perspective taking & $.078 * *$ & .021 & $.077 *$ & .020 \\
\hline Affective organizational commitment & .032 & .021 & $.033 *$ & .014 \\
\hline Self-monitoring & -.026 & .025 & & \\
\hline Gratitude & .036 & .020 & & \\
\hline Pastoral care & .023 & .043 & & \\
\hline Social identity (Johnson scale) & -.027 & .029 & & \\
\hline Social identity (Luhteman scale) & .006 & .020 & & \\
\hline Procedural fairness (Byrne scale) & .023 & .022 & & \\
\hline Perceived support & -.001 & .024 & & \\
\hline Procedural fairness (Niehoffpf scale) & .003 & .028 & & \\
\hline Trust & .023 & .020 & & \\
\hline Normative commitment & .006 & .014 & & \\
\hline Affective supervisory commitment & -.005 & .015 & & \\
\hline
\end{tabular}

Model 1 indicates enter method, Model 2 indicates backward entry

$*=p<.05 . * *=p<.01$

setting. Methods to increase organizational commitment exist in the extant literature. Bulut and Culha (2010) found the quality of training for employees explained variance in their levels of commitment towards that organization. More specifically, as well as providing high quality training, the authors report that employees need to be adequately supported during the training process in order to maximize commitment. In a university context, teaching provided by the faculty is akin to "training". Thus, it should be emphasized to staff not only the importance of high quality teaching, but also the additional support students require to assimilate the information- such as access to frequent office hours, and the assurance that contact/ questions are always welcome.

Pierro et al. (2013) have highlighted how transformational or "charismatic" leadership may impinge on this aspect of employees' affective commitment to their organization. This may be more challenging for universities to implement, as there is no simple way to encourage staff to be charismatic. Nevertheless, perhaps universities may like to increase the visibility of particularly magnetic staff if they wish to alter students' commitment, and accordingly their performance of pro-social behaviour.

The above mentioned strategies are perhaps not surprising; indeed most universities engage in some or all of these practices already. However, they are usually performed as part of the traditional university landscape rather than being grounded in psychology theory, and may lack the necessary formality and structure in order to maximize effectiveness. By examining our research here, university authorities can precisely target the facets of their institution that may facilitate student behaviour, and overall increase the pro-sociality of the student population.

\section{The Universality of Extra-Role Behaviours}

Pro-social behaviour has been examined in an organisational context, and in this paper we have investigated these behaviours in a university environment. What then are the key factors for the manifestation of these kinds of behaviours? Organizations and universities are similar in that they both contain large groups of individuals who work towards production of certain outputs. However, they also have many differences. First, students attending university pay to attend, whereas employees receive pay for their work. This investment may in fact facilitate pro-sociality, as individuals' tend to act in a more positive fashion towards endeavours they have a stake in (Seta et al. 1992). Second, whilst both collectives experience the entry of new members and the loss of older members, this membership flux operates in a much more predictable and systematic fashion at universities. Such an "open" group structure may undermine cooperation as it dilutes feelings of investiture and group cohesion (Burnette and Forsyth 2008). Previous research has also shown that as the end of an interaction draws near, there is a tendency for individuals to engage in more selfish behaviour (e.g. Heide and Miner 1992). Thus, we may expect that incidents of prosociality to be weaker towards the later part of students' university life. Third, organizational "output" is usually tangible, visible, and operates at a superordinate company level. At universities, none of these things are true; output is at the individual level (via the conferring of degree awards), and is considerably more ephemeral, in the form of "education". Fourth, the dynamics within each embedding system may be very different. Universities lend themselves to the formation of sub-groups; students are encouraged to join clubs and societies and to form strong social identities with fellow members. Sub-group formation is usually deleterious to cooperation with those outside of one's immediate sub-group (Huddy and Virtanen 1995). It is unlikely that the simple bringing together of large groups of people is enough to initiate prosociality; group size is usually negatively correlated with cooperation (Brewer and Kramer 1986). In future work then, we may like to examine what are the necessary infrastructure conditions that are required in order to observe sizeable manifestations of spontaneous pro-sociality in group members.

\section{Future Work}

As well as gaining insights in the minimal necessary conditions for eliciting pro-social behaviour from students, there are 
a number of other avenues for future research. First, we would like to investigate further why these specific predictors seem to be so influential. To do this, further qualitative work may be useful to get more insight into students' thinking. Second, we have outlined several interventions that may increase student pro-sociality performance. The use of such interventions could be formally tested to examine whether they are effective. Third, student pro-sociality could directed towards an institution generally or a specific person (Jahangir et al. 2004; Smith et al. 1983). We have not examined students' behaviour with this level of detail in this work; clearly future studies have scope to do so.

Finally, it would be enlightening to investigate to what extent self-reported behaviour aligns with students' actual behaviour. Although self-reports are ubiquitous in psychological research, there is a movement towards more direct measures of action in studies to ensure congruency between report and deed (e.g. Baumeister et al. 2007). By observing the pro-social (or otherwise) behaviours that students perform, we may better be able to predict what elicits them. Of course, this concept is rife with methodological and practical issues; nevertheless, it may be a further step in our understanding of what prompts the performance of selfless, non-rewarded behaviour amongst students attending university.

Acknowledgements This research was funded by a research grant from the Leverhulme Trust (grant number: RPG-2013-256). The authors would like to thank the Trust for funding this work.

\section{Compliance with Ethical Standards}

Ethical Approval All procedures performed in studies involving human participants were in accordance with the ethical standards of the institutional and/or national research committee and with the 1964 Helsinki declaration and its later amendments or comparable ethical standards.

Conflict of Interest On behalf of all authors, the corresponding author states that there is no conflict of interest.

Open Access This article is distributed under the terms of the Creative Commons Attribution 4.0 International License (http:// creativecommons.org/licenses/by/4.0/), which permits unrestricted use, distribution, and reproduction in any medium, provided you give appropriate credit to the original author(s) and the source, provide a link to the Creative Commons license, and indicate if changes were made.

\section{References}

Abele, S., Stasser, G., \& Chartier, C. (2010). Conflict and coordination in the provision of public goods: A conceptual analysis of continuous and step-level games. Personality and Social Psychology Review, 14(4), 385-401. https://doi.org/10.1177/1088868310368535.

Batson, C. D., Early, S., \& Salvarani, G. (1997). Perspective taking: Imagining how another feels versus imagining how you would feel. Personality and Social Psychology Bulletin, 23(7), 751-758. https:// doi.org/10.1177/0146167297237008.
Baumeister, R. F., Vohs, K. D., \& Funder, D. C. (2007). Psychology as the science of self-reports and finger movements: Whatever happened to actual behavior? Perspectives on Psychological Science, 2(4), 396-403. https://doi.org/10.1111/j.1745-6916.2007.00051.x.

Bettencourt, L. A., \& Brown, S. W. (2003). Role stressors and customeroriented boundary-spanning behaviors in serfvice organizations. Journal of the Academy of Marketing Science, 31(4), 394-408. https://doi.org/10.1177/0092070303255636.

Brewer, M. B., \& Kramer, R. M. (1986). Choice behavior in social dilemmas: Effects of social identity, group size, and decision framing. Journal of Personality and Social Psychology, 50(3), 543-549.

Brookes, K., Davidson, P. M., Daly, J., \& Halcomb, E. J. (2007). Role theory: A framework to investigate the community nurse role in contemporary health care systems. Contemporary Nurse, 25(1-2), 146-155. https://doi.org/10.5172/conu.2007.25.1-2.146.

Bruins, J. J., Liebrand, W. B., \& Wilke, H. A. (1989). About the saliency of fear and greed in social dilemmas. European Journal of Social Psychology, 19(2), 155-161.

Brunetto, Y., Farr-Wharton, R., \& Shacklock, K. (2011). Supervisorsubordinate communication relationships, role ambiguity, autonomy and affective commitment for nurses. Contemporary Nurse, 39(2), 227-239. https://doi.org/10.5172/conu.2011.39.2.227.

Bulut, C., \& Culha, O. (2010). The effects of organizational training on organizational commitment. International Journal of Training and Development, 14(4), 309-322.

Burnette, J. L., \& Forsyth, D. R. (2008). “I didn't do it:” Responsibility biases in open and closes groups. Group Dynamics, 12(3), 210-222. https://doi.org/10.1037/1089-2699.12.3.210.

Byrne, Z. S. (1999). How do procedural and interactional justice influence multiple levels of organizational outcomes. In annual meeting of the Society for Industrial and Organizational Psychology, Atlanta, GA.

Danheiser, P. R., \& Graziano, W. G. (1982). Self-monitoring and cooperation as a self-presentational strategy. Journal of Personality and Social Psychology, 42(3), 497-505.

Davis, M. (1980). A multidimensional approach to individual differences in empathy. JSAS Catalog of Selected Documents in Psychology, 10, 85-103.

Dawes, R. M., \& Messick, D. M. (2000). Social dilemmas. International Journal of Psychology, 35(2), 111-116.

De Cremer, D., Snyder, M., \& Dewitte, S. (2001). The less I trust, the less I contribute (or not)? 'The effects of trust, accountability and selfmonitoring in social dilemmas. European Journal of Social Psychology, 31(1), 93-107.

Eisenberger, R., Huntington, R., Hutchison, S., \& Sowa, D. (1986). Perceived organizational support. Journal of Applied Psychology, 71(3), 500-507. https://doi.org/10.1037/0021-9010.71.3.500.

Feather, N. T., \& Rauter, K. A. (2004). Organizational citizenship behaviours in relation to job status, job insecurity, organizational commitment and identification, job satisfaction and work values. Journal of Occupational and Organizational Psychology, 77(1), 81-94.

Flannelly, K. J., Galek, K., Tannenbaum, H. P., \& Handzo, G. F. (2007). A preliminary proposal for a scale to measure the effectiveness of pastoral care with family members of hospitalized patients. The Journal of Pastoral Care \& Counseling, 61(1-2), 19-29. https:// doi.org/10.1177/154230500706100103.

Hassan, S. (2013). The importance of role clarification in workgroups: Effects on perceived role clarity, work satisfaction, and turnover rates. Public Administration Review, 73(5), 716-725. https://doi. org/10.1111/puar.1210.

Heide, J. B., \& Miner, A. S. (1992). The shadow of the future: Effects of anticipated interaction and frequency of contact on buyer-seller cooperation. Academy of Management Journal, 35(2), 265-291.

Huddy, L., \& Virtanen, S. (1995). Subgroup differentiation and subgroup bias among Latinos as a function of familiarity and positive 
distinctiveness. Journal of Personality and Social Psychology, 68(1), 97-108.

Jahangir, N., Akbar, M. M., \& Haq, M. (2004). Organizational citizenship behavior: Its nature and antecedents. BRAC University Journal, l(20), 75-85.

Johnson, M. D., Morgeson, F. P., \& Hekman, D. R. (2012). Cognitive and affective identification: Exploring the links between different forms of social identification and personality with work attitudes and behavior. Journal of Organizational Behavior, 33(8), 1142-1167. https://doi.org/10.1002/job.1787.

Kamdar, D., McAllister, D. J., \& Turban, D. B. (2006). “All in a day's work": How follower individual differences and justice perceptions predict OCB role definitions and behavior. Journal of Applied Psychology, 91(4), 841-855. https://doi.org/10.1037/0021-9010. 91.4.841.

Koole, S. L., Jager, W., van den Berg, A. E., Vlek, C. A. J., \& Hofstee, W. K. B. (2001). On the social nature of personality: Effects of extraversion, agreeableness, and feedback about collective resource use on cooperation in a resource dilemma. Personality and Social Psychology Bulletin, 27(3), 289-301.

Lennox, R. D., \& Wolfe, R. N. (1984). Revision of the self-monitoring scale. Journal of Personality and Social Psychology, 46(6), 13491364. https://doi.org/10.1037/0022-3514.46.6.1349.

Luhtanen, R., \& Crocker, J. (1992). A collective self-esteem scale: Selfevaluation of one's social identity. Personality and Social Psychology Bulletin, 18(3), 302-318. https://doi.org/10.1177/ 0146167292183006.

Martinez, L. M. F., Zeelenberg, M., \& Rijsman, J. B. (2011). Behavioural consequences of regret and disappointment in social bargaining games. Cognition and Emotion, 25(2), 351-359. https://doi.org/10. 1080/02699931.2010.485889.

McCullough, M. E., Emmons, R. A., \& Tsang, J.-A. (2002). The grateful disposition: A conceptual and empirical topography. Journal of Personality and Social Psychology, 82(1), 112-127. https://doi. org/10.1037/0022-3514.82.1.112.

Meierhans, D., Rietmann, B., \& Jonas, K. (2008). Influence of fair and supportive leadership behaviors on commitment and organizational citizenship behavior. Swiss Journal of Psychology, 67(3), 131-141. https://doi.org/10.1024/1421-0185.67.3.131.

Meyer, J. P., \& Allen, N. J. (1991). A three-component conceptualization of organizational commitment. Human Resource Management Review, 1(1), 61-89. https://doi.org/10.1016/1053-4822(91)90011$\mathrm{Z}$.

Niehoff, B. P., \& Moorman, R. H. (1993). Justice as a mediator of the relationship between methods of monitoring and organizational citizenship behavior. Academy of Management Journal, 36(3), 527556. https://doi.org/10.2307/256591.

O'driscoll, M. P., \& Beehr, T. A. (2000). Moderating effects of perceived control and need for clarity on the relationship between role stressors and employee affective reactions. The Journal of Social Psychology, 140(2), 151-159. https://doi.org/10.1080/00224540009600454.

Ohnuma, S., Hirose, Y., Karasawa, K., Yorifuji, K., \& Sugiura, J. (2005). Why do residents accept a demanding rule? Fairness and social benefit as determinants of approval of a recycling system. Japanese Psychological Research, 47(1), 1-11. https://doi.org/10. 1111/j.1468-5584.2005.00267.x.

Pierro, A., Raven, B. H., Amato, C., \& Bélanger, J. J. (2013). Bases of social power, leadership styles, and organizational commitment. International Journal of Psychology, 48(6), 1122-1134. https:// doi.org/10.1080/00207594.2012.733398.

Podsakoff, N. P., Whiting, S. W., Podsakoff, P. M., \& Blume, B. D. (2009). Individual- and organizational-level consequences of organizational citizenship behaviors: A meta-analysis. Journal of Applied Psychology, 94(1), 122-141. https://doi.org/10.1037/ a0013079.
Rizzo, J. R., House, R. J., \& Lirtzman, S. I. (1970). Role conflict and ambiguity in complex organizations. Administrative Science Quarterly, 15(2), 150-163. https://doi.org/10.2307/2391486.

Robbins, T. L. (1995). Social loafing on cognitive tasks: An examination of the "sucker effect". Journal of Business and Psychology, 9(3), 337-342. https://doi.org/10.1007/BF02230973.

Rumble, A. C., Van Lange, P. A. M., \& Parks, C. D. (2010). The benefits of empathy: When empathy may sustain cooperation in social dilemmas. European Journal of Social Psychology, 40(5), 856-866.

Sawyer, J. E. (1992). Goal and process clarity: Specification of multiple constructs of role ambiguity and a structural equation model of their antecedents and consequences. Journal of Applied Psychology, 77(2), 130-142. https://doi.org/10.1037/0021-9010.77.2.130.

Schappe, S. P. (1998). The influence of job satisfaction, organizational commitment, and fairness perceptions on organizational citizenship behavior. The Journal of Psychology, 132(3), 277-290. https://doi. org/10.1080/00223989809599167.

Schnake, M. E. (1991). Equity in effort: The "sucker effect" in co-acting groups. Journal of Management, 17(1), 41-55. https://doi.org/10. 1177/014920639101700104.

Schreiber, J. B., Nora, A., Stage, F. K., Barlow, E. A., \& King, J. (2006). Reporting structural equation modeling and confirmatory factor analysis results: A review. The Journal of Educational Research, 99(6), 323-338. https://doi.org/10.3200/JOER.99.6.323-338.

Seta, J. J., Seta, C. E., \& Donaldson, S. (1992). The implications of a resource-investment analysis of goal value for performance in audience and solitary settings. Basic and Applied Social Psychology, 13(2), 145-164. https://doi.org/10.1207/s15324834basp1302_1.

Shapiro, J., Rucker, L., Boker, J., \& Lie, D. (2006). Point-of-view writing: A method for increasing medical students' empathy, identification and expression of emotion, and insight. Education for Health (Abingdon, England), 19(1), 96-105. https://doi.org/10.1080/ 13576280500534776.

Shivers-Blackwell, S. L. (2004). Using role theory to examine the determinants of transformational and transactional leader behavior. Journal of Leadership and Organizational Studies, 10(3), 41-50. https://doi.org/10.1177/107179190401000304.

Smith, C. A., Organ, D. W., \& Near, J. P. (1983). Organizational citizenship behavior: Its nature and antecedents. Journal of Applied Psychology, 68(4), 653-663.

Stouten, J., De Cremer, D., \& Van Dijk, E. (2006). Violating equality in social dilemmas: Emotional and retributive reactions as a function of trust, attribution, and honesty. Personality and Social Psychology Bulletin, 32, 894-906.

Van Laar, D., \& Easton, S. (1994). Pastoral care in tertiary education: Experiences of lecturers helping students at a new university. Counselling Psychology Quarterly, 7(1), 83-89. https://doi.org/10. 1080/09515079408254136.

Van Vugt, M., Van Lange, P. A. M., \& Meertens, R. M. (1996). Commuting by car or public transportation? A social dilemma analysis of travel mode judgements. European Journal of Social Psychology, 26(3), 373-395. https://doi.org/10.1002/(SICI)10990992(199605)26:3<373::AID-EJSP760>3.0.CO;2-1.

Winefield, H. R., \& Chur-Hansen, A. (2000). Evaluating the outcome of communication skill teaching for entry-level medical students: Does knowledge of empathy increase? Medical Education, 34(2), 90-94. https://doi.org/10.1046/j.1365-2923.2000.00463.x.

Yamagishi, T. (1986). The provision of a sanctioning system as a public good. Journal of Personality and Social Psychology, 51(1), 110 116. https://doi.org/10.1037/0022-3514.51.1.110.

Publisher's Note Springer Nature remains neutral with regard to jurisdictional claims in published maps and institutional affiliations. 